\title{
"SI PUDIERA CONVERTIRME EN HOMBRE". GÉNERO, POLÍTICA Y SOCIEDAD: LA REDEFINICIÓN DE LO FEMENINO EN EL LARGO 48 ITALIANO
}

\author{
"IF I COULD BECOME A MAN". GENDER, POLITICS \\ AND SOCIETY: THE REDEFINITION OF FEMININITY \\ DURING THE LONG 1848 IN ITALY
}

\author{
Matteo Morandini \\ Università Roma II, Tor Vergata
}

\section{RESUMEN}

Durante la revolución italiana y europea de 1848, hicieron su aparición nuevos medios o estilos artísticos que entraron rápidamente en el arsenal político que caracterizó la oposición ideológica entre el movimiento nacionalista italiano y la Curia romana. Del análisis de tipologías documentales específicas e inusuales (caricatura, pintura y ficción ficticia), emergen claramente algunos núcleos temáticos que estructuran, en ambos lados, la retórica política y la disputa ideológica: la noción de personas, el anticlericalismo o el anti-republicanismo, pero sobre todo la nueva definición de masculinidad y feminidad, con la definición de los roles correspondientes. A este respecto, la atención obsesiva a la corporeidad femenina y su exposición pública no deseada, que se puede encontrar en ambas producciones, parece referirse al fenómeno más amplio de la afirmación progresiva de la sociedad burguesa y su sistema de valores (nacionalismo) así como la tenaz resistencia del clero destinado a mantener el control sobre las instituciones, la familia ante todo, que consideraba el verdadero depósito de la fe y la base de las relaciones sociales.

Palabras clave: Risorgimento, mujeres, sociedad burguesa, Iglesia católica, Nacionalismo, Caricatura, Novela.

\footnotetext{
ABSTRACT

During the Italian and European revolution of 1848, new artistic fields and styles appeared which rapidly became part of the political arsenal which characterised the ideological opposition between the Italian nationalist movement and the Roman Curia. From the analysis of specific and unusual documental typologies (caricature, painting and fiction), some thematic cores clearly emerge which structure, on both sides, the political rhetoric and the ideological dispute: the notion of people, anticlericalism or anti-republicanism, but above all the
} 
new definition of masculinity and femininity, with the corresponding definition of roles. In this respect, the obsessive attention to feminine corporality and its undesired public explosion, which can be found in both productions, appears to refer to the wider phenomenon of the progressive affirmation of bourgeois society and its system of values (nationalism) and so the tenacious resistance of the clergy aimed at maintaining control over institutions, above all the family, considered to be the true holder of faith and the base of social relations.

Keywords: Risorgimento, women, bourgeois society, Catholic Church, nationalism, cartoon, novel.

\section{RESUM \\ "SI POGUÉS CONVERTIR-ME EN HOME". GÈNERE, POLÍTICA I SOCIETAT: LA RE-DEFINICIÓ D'ALLÒ FEMENÍ EN EL LLARG 48 ITALIÀ}

Durant la revolució italiana i europea de 1948, van aparèixer nous medis o estils artístics que entraren ràpidament a l'arsenal polític que va caracteritzar l'oposició ideològica entre el moviment nacionalista italià i la Cúria romana. Des de l'anàlisi de tipologies documentals específiques e inusuals (caricatura, pintura i ficció fictícia), emergeixen clarament alguns nuclis temàtics que estructuren, en ambdues bandes, la retòrica política i la disputa ideològica: la noció de persones, l'anticlericalisme o l'antirepublicanisme, però sobretot la nova definició de masculinitat i feminitat, amb la diferenciació dels rols corresponents. A aquest respecte, l'atenció obsessiva a la corporeïtat femenina i la seva exposició no desitjada, que es pot trobar en ambdues produccions, pareix referir-se al fenomen més ampli de l'afirmació progressiva de la societat burgesa i el seu sistema de valors (nacionalisme) així com la tenaç resistència del clergat destinat a mantenir el control sobre les institucions, la família abans de res, que considerava el veritable dipòsit de la fe i la base de les relacions socials.

Paraules clau: Gènere, revolució 1948, art, feminitat, Itàlia. 
La revolución de 1848 en la península italiana ha centrado la atención historiográfica en los últimos años, después de haber sido un objeto de investigación soslayado durante mucho tiempo, considerado poco estimulante, o incluso propicio a resbalones retóricos nada convenientes. ${ }^{1}$ La atención renovada que ha despertado la unificación nacional está en deuda con la llamada Nueva historiografía sobre el Risorgimento. A su vez, ésta debe mucho a Alberto Mario Banti, ${ }^{2}$ que ha tenido el mérito de haber presentado una nueva propuesta interpretativa tomada del giro lingüístico, llegado a ltalia unos años más tarde que al norte de Europa. En este nuevo panorama, se ha reservado un amplio espacio para la idea de nación, la antropología, la religión política y, por último, pero no menos importante, para el género. Simonetta Soldani e llaria Porciani, entre otras, han subrayado la importancia de la cesura del siglo XIX en la redefinición del papel

1 Cf. BANTI, Alberto Mario et alii (2011), Atlante culturale del Risorgimento. Lessico del linguaggio politico dal Settecento all'Unità, Bari, Laterza, 2011; y BANTI, Alberto Mario y GINSBORG, Paul (eds.) (2007), Storia d'Italia. Annali 22, Il Risorgimento, Einaudi, Turín.

2 BANTI, Alberto Mario (2011), La nazione del Risorgimento, Einaudi, Turín. 
femenino, en el disciplinamiento, ${ }^{3}$ como escribe la primera historiadora, que las mujeres italianas sufrieron en el momento de la eclosión nacional y, sobre todo, para ese momento. Su enfoque se remite a las enseñanzas de George Mosse, a las herramientas heurísticas de Michel Foucault y a las contribuciones de la historia de género.

La presente contribución retoma ese hilo en un intento de vincular a él tipografías documentales poco explotadas y que casi siempre se tratan de manera exclusiva e independiente. En otras palabras, se pretende analizar cómo las caricaturas, las pinturas y la literatura de ficción han narrado o utilizado lo femenino en los trastornos revolucionarios y nacionales, y tanto en la acción concreta de las mujeres en la escena revolucionaria como en su dimensión simbólica. En este sentido, también pretendemos ampliar el análisis a las producciones de carácter reaccionario vinculadas de diversos modos a la Curia romana y a sus portavoces, un aspecto bastante silenciado en la historiografía reciente.

Como tendré la oportunidad de mostrar, las convergencias y la intertextualidad entre las dos corrientes opuestas no fueron nada infrecuentes, muy al contrario, revelan una repetición clara -y sorprendente- de patrones y estrategias de comunicación, teniendo en cuenta las distancias ideológicas y la búsqueda de objetivos políticos antitéticos. Esta confrontación se centra en la mujer entendida como alma de lo doméstico, el tejido de la familia, y a fin de cuentas como un territorio de enfrentamiento entre el movimiento nacional y la jerarquía eclesiástica en la cuestión más amplia del surgimiento de la sociedad burguesa, que a través de los mitos del nacionalismo y de la nueva moralidad familiar comenzaron a erosionar las bases tradicionales de la devoción y el control del clero. ${ }^{4}$ Por lo tanto, aquí se subrayará cómo se estructuró, en medio de la disputa ideológica, una

3 SOLDANI, Simonetta y PORCIANI, llaria (1999), "Donne e nazione nella rivoluzione italiana del 1848", Passato e Presente, vol. 46 (1999), p. 84; SOLDANI, Simonetta y PORCIANI, llaria (2002), "Italiane! Appartenenza nazionale e cittadinanza negli scritti di donne dell'Ottocento", Genesis, vol. 1, pp. 85-124; y PORCIANI, Ilaria, "Disciplinamento nazionale e modelli domestici nel lungo Ottocento: Germania e Italia a confronto", en BA. Como tendré la oportunidad de ilustrar las convergencias, la intertextualidad entre las dos partes opuestas será todo menos rara y señalará una repetición evidente y repetitiva de patrones y estrategias de comunicación, teniendo en cuenta las distancias ideológicas y los objetivos políticos antitéticos.

4 Cf. ISNENGHI, Mario y CECCHINATO, Eva (eds.) (2008), "Fare I'Italia: unità e disunità nel Risorgimento", en Gli italiani in guerra. Conflitti, identità, memorie dal Risorgimento ai nostri giorni, vol. I, Utet, Turín. 
fuerte convergencia retórica entre los contendientes que certifica la existencia de un discurso efectivo, de una metodología narrativa considerada unánimemente ganadora, inaugurada primero por los actores revolucionarios y luego adoptada por oradores eclesiásticos y reaccionarios. Mediante el uso de la idea de la mujer, se libró la batalla por la imposición de una determinada opción ideológica y la afirmación del sistema de valores burgués, entre cuyos puntos clave figuraban la familia y el papel exclusivamente doméstico reservado a las mujeres.

\section{LA EBRIEDAD EFIMERA DE LAS BARRICADAS: LA MEMORIALÍSTICA}

Un elemento que recorre transversalmente todas las obras de memorias escritas después del 48 por actores revolucionarios más o menos prominentes es la atmósfera de concordia y unanimidad momentáneas que acompañaron a los trastornos políticos en toda la Península, desde el Milán de los Cinco Días a la Roma republicana de 1849. Como escribe Giovanni Visconti Venosta, observador participante en la revolución milanesa

Dappertutto era la stessa cosa; come in una polveriera dove si fosse dato fuoco a una miccia nel tempo stesso, in ogni città, in ogni borgata, in ogni villaggio, ognuno a suo modo aveva fatto la sua rivoluzione, quasi vi fosse stata un'intesa, e con gli stessi caratteri di concordia, di entusiasmo, e talora di imprevidenza generosa e ingenua. ${ }^{5}$

En este ejemplo queda claro que se invoca a la patria mediante un llamamiento retórico a la unidad, la suspensión de altercados y la superación temporal de las barreras sociales y culturales tradicionales. Incluso aquellos que, por razones de edad, religión o género, estaban tradicionalmente excluidos de la vida pública encontraron su espacio en la celebración unánime del cuerpo de la nación. También les ocurrió a las mujeres en armas, desde Rosa Verza hasta Domenica Luigia Sassi, que vivieron un momento contradictorio e inesperado de protagonismo entre los silbidos de las balas en las barricadas. El caso de Sassi es sintomático: casada y de 24 años de edad, "fu la prima a fare le barricate nel suo quartiere, strappata di mano una pistola ad un soldato, intimò ad altri cinque d'arrendersi, i quali presi, furono consegnati nella caserma dei finanzieri [...]. Vestitasi da vomo, al

5 VISCONTI VENOSTA, Giovanni (1904), Ricordi di gioventù. Cose vedute o sapute 18471860, Tip. Ed. L. F. Cogliati, Milán, 1904, pp. $115-116$. 
borgo di S. Croce arrestò tre guardie di polizia" y "fattasi conduttrice di circa 100 vomini, insegui una mano di fanti e di cavalieri, e questo sotto una pioggia di palle", hasta que por fin sostuvo "una lunga fucilata contro i croati". ${ }^{6}$

Esta mujer, la del 48 italiano, aparece dividida entre su papel de madre/ hermana/esposa y las ansias políticas y de autonomía personal que aquellos primeros espacios de libertad parecían propiciar. Así, la joven romana Colomba Antonietti, "già avvinta con nodi maritali, soccorreva lo sposo che a riparar le breccie era andato, e con ardore s'adoprava là dove più ferveva il pericolo, lasciando incerto il riguardante se in lei potesse più l'amore che al suo sposo l'arvinceva o quello fortissimo che alla sua patria la lega$v a^{\prime \prime}$. Dividida entre la vocación pública y los deberes conyugales, seguía a su marido "in tutte le fazioni di guerra, a cui per l'Italia s'avventurava, dividendo con lui fatiche e pericoli". En el fragor de la batalla mantuvo una calma inusual, "serena, tranquilla, impavida ella rimaneva al suo posto, ed ogni volta che i suoi sguardi s'incontravano in quelli del suo sposo [...] una fiamma di contento parea salirle al viso quasi inorgoglito avesse di quella sua carita di patria. Alcuni soldati caddero in quella morti a suoi piedi, né per le nuove istanze fattele ella volle ritirarsi; vi fu un momento anzi in cui alla fe' un passo verso il marito per fornirlo degli strumenti che aveva addimandati, e una palla di cannone la percosse adempiente quell'atto di amore coniugale". La conducta ejemplar y patriótica de esta mujer culminó plenamente con su dramática despedida del mundo: hincada de rodillas, "levò le mani e gli occhi al cielo e spirò dopo un minuto gridando 'Viva I'Italia'. I suoi leggiadri lineamenti si copersero del pallore della morte, ma il sorriso non si scompagnò dalle sue labbra che anche in quell'eterno silenzio esprimer pareano l'amore e la fede, che collegata l'aveano in vita alla sua famiglia e alla sua patria". En el cortejo fúnebre que se improvisó en su honor en Roma, "il popolo trasse in folla dietro al feretro coperto di bianche rose, simbolo del candore di lei spenta sì crudelmente nel fiore della giovinezza" ${ }^{\text {? }}$

6 CATTANEO, Carlo (1850-51), Archivio triennale delle cose d'Italia dall'avvenimento di Pio IX all'abbandono di Venezia, Tipografia Elvetica, Capolago, vol. I, p. 396.

7 RUSCONI, Carlo (1850), La Repubblica romana (del 1849), Editore Cassone, Turín, vol. II, pp. 158-159. Otro caso famoso es el de Battistoni-Sassi, también una mujer en armas, que treinta años después de los acontecimientos seguía sorprendiendo a Giuseppe Bollini. El relato retoma algunos de los temas centrales sobre el papel de las mujeres en el Risorgimento, su raro- protagonismo y las formas en que se expresó su voluntad: "poco dopo sortì dalla stessa casa n. 23 una donna (brunetta) vestita da vomo [...] che andò a sedersi accanto all'vomo che 
Con mucha más frecuencia, no obstante, el papel reservado al género femenino era más tranquilo y se representaba en la sombra, desde la confección de cartuchos hasta los trabajos de costura. ${ }^{8}$ Pasado el primer entusiasmo, en los meses siguientes los espíritus más fogosos y conflictivos tuvieron que replegarse a la plácida vida cotidiana. Se acabó la efervescencia del estallido revolucionario, en que todos esos nuevos actores habían sido momentáneamente lanzados al centro de la arena política, a las calles y barricadas. ${ }^{9}$ En Venecia, la petición de un grupo de mujeres de ser admitidas en la Guardia Cívica, símbolo y emblema de la identidad política y militar, se consideró inapropiada y fue rechazada, mientras que en Roma la participación femenina en la guerra patria se recondujo y se restringió a la confección de banderas, a la recaudación de fondos y a servicios más femeninos, como la asistencia a los heridos y enfermos. ${ }^{10}$ De hecho, los recientes y fugaces momentos de liberación y licencia hicieron que las mujeres constatasen y padecieran más su condición. En Como, la republicana Luisa De Orchi, apasionada seguidora de Garibaldi, que pintó y vendió acuarelas para financiar las empresas del héroe, al escribir a una amiga le confesaba: "Se potessi diventar vomo, sarei soldato, così mi tocca d'ingojare il calice amaro delle dure abnegazioni, cui donna è condannata" . ${ }^{11}$ Eso no quita que, durante ese momento de apogeo nacional, se abriesen a las mujeres, siquiera momentáneamente, espacios temporales de discurso y acción y, en cualquier caso, se les reconociera un papel visible en las liturgias civiles y las ocasiones solemnes, así como un lugar en la celebración

la stava aspettando. Di un tratto si senti gridare il solito 'armi da fuoco in Borgo S. Croce'. La brunetta, che seppi poi essere la Sassi, scattò in piedi, tolse il fucile di mano al suo compagno e passò ridendo nella barricata di S. Croce. La vidi poi sopra un ballatoio di legno dirigere colpi di fucile sul bastione" (citado en BORTOLOTTI, Michela ("Le piazze e le barricate nel Quarantotto",en Fare I'Italia, p. 504).

8 VISCONTI VENOSTA, Ricordi, p. 113

9 Sin embargo, poco después, "i nobili tornarono a sentirsi diversi dai cittadini, i ricchi dai poveri, gli aristocratici della moda dagli vomini tagliati alla buona; ricomparvero le livree e gli stemmi sulle carrozze, la sostenutezza coi dipendenti; i titoli". También los judíos, acogidos por el fervor revolucionario en la celebración de la familia patria y en los abrazos de marzo, experimentarían de nuevo la hostilidad popular tras su incorporación a las filas de la Guardia Cívica. AMBROSOLI, Luigi (ed.) (1969), La insurrezione milanese del marzo 1848, Ricciardi, Milán-Nápoles, pp. 103-104.

10 FRANCIA, Enrico (2012), 1848: la rivoluzione del Risorgimento, II Mulino, Bolonia, pp. 283 296.

11 BORTOLOTTI, Le piazze e le barricate nel Quarantotto, p. 508. 
de la cuerpo de la nación junto con otros actores generalmente excluidos de la vida pública. ${ }^{12}$ En los desfiles, en los Te Deum y en las procesiones, las mujeres no sólo intervinieron como espectadoras, sino que formaron junto a los representantes de las instituciones y participaron activamente en las mismas actividades públicas que los hombres. Esta presencia visible de las mujeres fue considerada legítima, e incluso necesaria, por algunos líderes patriotas. La inclusión en la vida pública de quienes normalmente eran ajenos a ella confirmaba y reforzaba la tendencia a la unanimidad de la vida política del Risorgimento, al menos en sus fases revolucionarias. La legitimidad de un papel público para las mujeres se inscribe plenamente en ese discurso nacional-patriótico "che attribuisce alla rinascita della nazione un carattere morale e civile ancora che politico" ${ }^{13}$ que llama a toda la comunidad a participar activamente..., pero que al mismo tiempo define rígidamente los roles de género. ${ }^{14}$ Por lo tanto, a las mujeres se les concedió un papel patriótico que desempeñaron principal, si no exclusivamente, en el ámbito doméstico, como madres, esposas o hermanas: ${ }^{15}$ "L'Angelo della Famiglia è la Donna. Madre, sposa, sorella, la Donna è la carezza della vita" ${ }^{16}$ Su aparición en la escena debía basarse en estos valores y le-

12 FRUCl, Gian Luca (2006), "Cittadine senza cittadinanza. La mobilitazione femminile nei plebisciti del Risorgimento (1848-1870)", Genesis, vol. 2, pp. 21-55; y FRUCl, Gian Luca (2007), "Il sacramento dell'unità nazionale. Linguaggi, iconografia e pratiche dei plebisciti risorgimentali (1848-1870)", en BANTI y GINSBORG (eds.), Storia d'Italia. Annali 22, pp. 567-605.

13 Citado en FRANCIA, 1848: la rivoluzione del Risorgimento, p. 284.

14 BIZZOCCHI, Roberto (2007), "Una nuova morale per la donna e per la famiglia", en BANTI y GINSBORG (eds.), Storia d'Italia. Annali 22, pp. 87 y ss.; y BANTI, Alberto Mario (2005), L'onore della nazione. Identità sessuali e violenza nel nazionalismo europeo dal XVIII secolo alla Grande Guerra, Einaudi, Turín,.

15 Es el caso, por ejemplo, de las mujeres de Dolo, que con motivo de la organización del plebiscito de anexión de 1866, presentaron sus solicitudes de participación basando la legalidad de su discurso en haber compartido emocionalmente el destino de sus padres, hijos y hermanos: "Le donne del distretto di Dolo che divisero i dolori e le umiliazioni dei padri, dei fratelli, degli sposi, dei figli durante l'austriaca tirannia, vollero pure partecipare della gioia del sesso maschile chiamato alla fortuna di dichiarare la sua volontà" (Aviso a la población de la comisión dfemenina por el plebiscito de Dolo, Venecia) también: "Anche noi donne italiane abbiamo diritto e dovere di esprimere il nostro voto [...]. Abbiamo diviso i dolori, i tormenti, le umiliazioni dei nostri padri, dei fratelli, degli sposi dei figli, abbiamo pianto con essi e forse più di essi [...] perché oggi non prenderemmo parte attiva alla loro gioia?". En MINISTERIO (1968), Gli Archivi dei regi commissari nelle province del Veneto e di Mantova 1866, II, Documenti, Ministero dell'Interno, Roma, p. 138.

16 MAZZINI, Giuseppe (1860), Doveri dell'uomo, [s. e.], Londres [Lugano], p. 66. 
gitimarse por ellos, sin subvertirlos desde un punto de vista político y social. Así, en el periódico romano La donna italiana se pedía a las lectoras que animaran a sus padres, hijos y consortes "a volare sui campi di battaglia" y "a cogliervi o la palma del martirio o il lauro della vittoria". ${ }^{17}$

Para corroborar el poder evocador de esta llamada, se proponía el modelo ejemplar de una madre de Brescia que había exhortado a sus hijos de este modo: "salvate la patria, e non tornate nelle mie braccia che morti e vincitori. ${ }^{18}$ El surgimiento de protagonismos femeninos como los de Caterina Franceschi Ferrucci y Cristina di Belgioioso aparece como diametralmente opuesto. En toda la Península, un gran número de mujeres se alzaron en armas y decidieron participar, como sus esposos y hermanos, en la virilidad guerrera y patriótica, y a pesar de ello las mismas heroínas combatientes vivieron con incomodidad o disgusto su condición de mujeres en armas, hasta el punto de elegir vestirse de hombres para participar en las acciones bélicas. ${ }^{19}$ Incluso las mujeres a las que no se les permitió este tipo de protagonismo expresaron esa desazón respecto a su condición femenina. Por ejemplo, la veneciana Maddalena Montalban Comello confesaba dolorosamente a Garibaldi su impotencia, porque "la natura mi fece il torto di farmi donna, perché il nostro sesso è pieno di schiavitü". ${ }^{20}$

La necesidad de disfrazarse de hombre o de externalizar el rechazo a la propia condición de género manifiestan la conciencia de que la rígida dicotomía de los roles sexuales ahogaba el potencial femenino, en un disciplinamiento que llevó a "avvertire alle donne [...] un senso di ingiustizia per

17 DE LONGIS, Rosanna (2002), "La donna italiana. Un giornale del 1848", Genesis, vol. 1, p. 262.

18 DE LONGIS, "La donna italiana. Un giornale del 1848", p. 289.

19 Así ocurrió con Domenica Luigia Sassi, piamontesa de veinticuatro años que "fu la prima a fare le barricate nel suo quartiere [...] vestitasi da uomo, al borgo si S. Croce arrestò tre guardie di polizia" e "fattasi conduttrice di circa 100 uomini, inseguì una mano di fanti e cavalieri, e questo sotto una pioggia di palle [...] e sostenne, unita a vari pompieri, una lunga fucilata contro i croati" (Archivio triennale, III, p. 396). Se pueden hallar otros rastros -no muchos, a decir verdad- en monumentos patrióticos: el protagonismo guerrero de Rosa Verza, que murió como mártir, asesinada por los disparos de cañones de los austriacos, o el heroísmo, dividido entre el deber conyugal y la exposición política y militar, de Colomba Antonietti. Véanse respectivamente MONTANELLI, Giuseppe (1853), Memorie sull'Italia e specialmente sulla Toscana dal 1814 al 1850, Società Editrice Italiana, Turín, vol, II, p. 439; y RUSCONI, La repubblica romana, pp. 157-159.

20 FRANCIA, 1848: la rivoluzione del Risorgimento, p. 293. 
l'esclusione [...]. Di qui il paradosso [...] di percepirsi come cittadine senza cittadinanza, costantemente in bilico fra comunità egualitaria immaginata e aspirazioni emancipazioniste". ${ }^{21}$

\section{El 48 en IMÁGeNeS: eNTRE GÉNERO Y POLÍTICA}

Ahora bien, el largo 48 italiano y su relato no fueron prerrogativa única de las memorias; muy al contrario, tanto la caricatura, un formato que nace y se expande en este momento, ${ }^{22}$ como la pintura $^{23}$ dedicaron, a pesar de sus importantes diferencias técnicas e iconográficas, una atención especial a los trastornos políticos que tenían lugar y al papel desempeñado, concreta o simbólicamente, por las mujeres. Aquí el análisis se centra en la producción de los soldados-pintores, unas figuras decisivas, porque combinaron la pintura en el campo de batalla con el activismo democrático y nacionalista, concretamente en cuatro publicaciones periódicas de caricaturas de particular interés. A excepción del milanés Lo Spirito Folletto, se trata de dos periódicos satíricos ilustrados romanos que establecen entre sí un constante juego de espejos, con alusiones y respuestas polémicas y políticas: Don Pirlone, ${ }^{24}$ revista democrática que acompañó y celebró la efímera República Romana de 1849, y su contrapunto reaccionario, la Grande Riunione, ${ }^{25}$ una obra anónima y colectiva que nació con el objetivo declarado de refutar y criticar al periódico satírico republicano y, por ende, la obra de la revolución romana. Por último, se tendrá en cuenta Don Pirlone a Roma, ${ }^{26}$ una obra colectiva publicada en varios volúmenes

21 FRUCl, "Cittadine senza cittadinanza", p. 23.

22 MORACHIOLI, Sandro (2013), L'Italia alla rovescia. Ricerche sulla caricatura giornalistica tra il 1848 e l'Unità, Edizioni della Normale, Pisa; AAVV (1998), Le rivoluzioni del 1848. L'Europa delle immagini:caricatura e illustrazione tra storia e arte, Associazione Torino Ccittà Ccapitale Europea, Turín; MAGGIO SERRA, Rosanna (2005) "Disegno, grafica e fotografia tra lotta ideologica, comunicazione mediatica e nuovi saperi", en HANSMANN, Martina (ed.), Pittura italiana dell'Ottocento, Marsilio, Venecia, 2005, pp. 349-366; y MAGGIO SERRA, Rosanna (1980), "La naissance de la caricature de presse en Italie et le journal turinois 'll Fischietto'", Histoire et Critique des arts, vol. 13-14, pp. 135-158.

23 MARINI CLARELLI, Maria Vittoria, SISI Carlo y MAZZOCCA, Fernando (eds.) (2008), L'Ottocento. Da Canova al Quarto stato, Skira, Milán; y MAZZOCCA, Fernando (ed.) (2010), 1861. I pittori del Risorgimento, Skira, Milán.

24 Don Pirlone: giornale di caricature politiche, Roma, 1848-1849.

25 Grande riunione tenuta nella sala dell'ex Circolo popolare in Roma, Roma, 1849.

26 PINTO, Michelangelo (1853), Don Pirlone a Roma. Memorie di un italiano dal 1 settembre 1848 al 31 dicembre 1850, Tipografia del Progresso, Turín, vol. I. 
en Turín en los años inmediata posteriores al colapso del 48 italiano y que, al completar los propósitos de su antecesor romano, se presenta como una interpretación general, una colección de juicios sobre los acontecimientos políticos romanos e italianos, así como una respuesta democrática a las invectivas clericales y antirrepublicanas de la Grande Riunione.

A primera vista, la producción caricaturesca del 48 y su retrospectiva parecen ignorar por completo lo femenino: son pocas las ilustraciones donde aparecen las mujeres, que muy raramente constituyen el objeto principal del discurso. Sin embargo, existen algunas excepciones, tanto más significativas cuanto que se refieren a la condición de las mujeres en el Risorgimento y al papel que se les reservó: obsérvese por ejemplo la ilustración de Don Pirlone a Roma titulada "Una generosa vendetta":

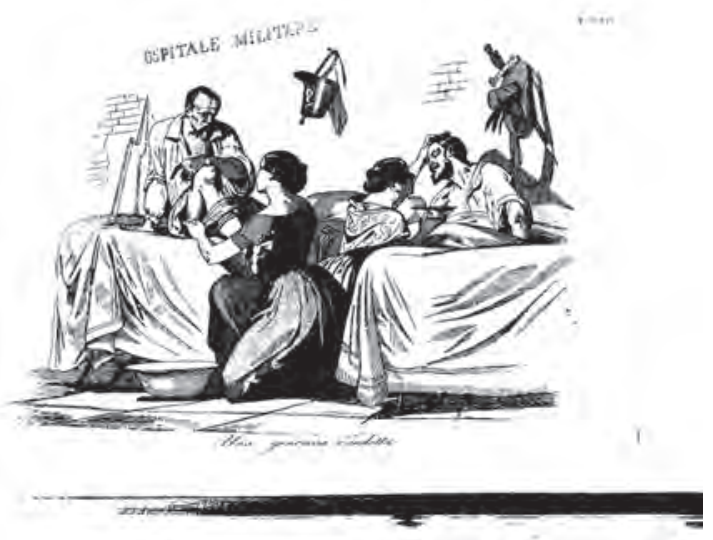

Fig. 1.

Estamos ante un juego continuo de alusiones mutuas entre las dos publicaciones posteriores al 48 , y por ellas el grabado puede interpretarse como una respuesta a la calificación nada amable que la Grande Riunione había reservado para las organizadoras ${ }^{27}$-entre ellas, una admiradora entusias-

27 No era un caso aislado. Baste con observar la sabrosa ilustración que la Grande Riunione dedicó a los principales actores revolucionarios de la Roma republicana (entre los que destacan los triunviros Mazzini, Armellini y Saffi), retratos como de costumbre caricaturescos, con rasgos zoomórficos, entre los que destaca la principal organizadora del servicio de ambulancias, la famosa patriota Cristina Trivulzio di Belgioioso: ella y sus asociados son retratados, en una alusión misógina no demasiado refinada, como gansos. 
ta de Garibaldi, la americana Margaret Fuller- del comité de gestión de las ambulancias. Léase el diálogo que sostienen Cassandrino, un personaje popular de orientación reaccionaria, y su interlocutor Apollonio:

APOL. Ma per i Feriti v'erano ampli e moltiplici Ospedali con medici, Chirurghi, e Farmacisti, e Donne

CAS. Eh! Capisco: le sorelle della carità...

APOL. Carità? Non erano Sorelle, no; erano in grandissima parte, non tutte, mogli da maritarsi a chi le voleva, senza testimoni, e senza curati. Femine dissolute, la cui Biografia dovrebbe scriversi dal Casti; la cui fama le circonda costante, come un aureola, come un nembo, che è il distintivo dei servi di Dio, per esse, è una riputazione da Lupanara, che si odora da lontano, come quel Cavallo che da lunge odora la Guerra. Pio IX che in Gaeta sapeva le più intime particolarità di questi Satanici Ospedali [...] scriveva agli arcivescovi e Vescovi d'italia in queste precise tremende parole: "Spesse volte gli stessi sciagurati infermi, privi affatto d'ogni soccorso religioso, nell'istante supremo della morte furono costretti ad esalare l'ultimo sospiro in mezzo alle inique seduzioni d'una meretrice sfacciata". So, e con certezza io so, che queste parole abbiano fatto effetto d'una spina di pesce in gola a molte signore, che si erano recate dai Malati Militari; ma direi loro che fu improvvido assai quell'andare ove dominava una Belgioioso, una...una...

CAS: Non mormorate fra i denti. Dite apertis verbis.

APOL: Non posso. Perché sono nomi di amiche vostre. Una è certa vedova maritata vecchia matta..

CAS: Ho capito. Ho capito. Mi pare l'ultimo giorno della Fiera di Sinigaglia: quello ch'è fatto, è fatto.

APOL: L'altra è una bella Matrona Girovaga. Non vi dico fosse impudica; no, ma..è certo, che procurava ai malati Libri disonesti, e anticattolici [...] V'era qualche comica, che arrendevole si prestava a carezze indecenti. Che vi si fossero introdotte delle Donne da prezzo è noto pur troppo! ${ }^{28}$

Es bastante probable que la "vedova maritata vecchia matta" fuese Fuller, corresponsal del periódico neoyorquino Tribune y casada hacía poco con el marqués Giovanni Angelo Ossoli. Resulta evidente que el texto está re- 
pleto de dobles sentidos y de referencias sexuales veladas o explícitas, así como que éstas son los vectores principales del mensaje, al mismo tiempo político y social: el libertinaje revolucionario se presenta como el mayor obstáculo para la convivencia promiscua de hombres y mujeres. La ilustración de Masutti parece revisar, aunque no desmentir, el sobrentendido. En realidad, y a pesar de ser enemigos, los militares franceses "indistintamente confortati dalle stesse attenzioni", 29 son púdicamente vendados y curados por las voluntarias organizadas por Cristina Belgioioso, una tarea que, diga lo que diga la publicación reaccionaria, se encuentra entre las pocas socialmente aceptadas durante el Risorgimento. Aunque sea a duras penas. Como ya se ha dicho, se reserva a las mujeres la gestión más segura del ámbito doméstico, desde el papel de engendradora al de educadora en los valores nacionales, así como, a lo sumo, las labores de costura de uniformes y banderas o de confección de cartuchos, tareas rigurosamente confinadas a la oscuridad del hogar. Otros protagonismos -excepciones aparte- estaban severamente prohibidos o se mirababn con malos ojos, como demuestran las ilustraciones irónicas y machistas aparecidas en 1848 en Lo Spirito Folletto sobre la Guardia Civica Femminile, un cuerpo que, de todos modos, no llegó a organizarse.

Aquí, al activarse una analogía poco sorprendente con el lenguaje reaccionario de la Grande Riunione, el rasgo humorístico se vincula a lo sexual, a la fragilidad emocional de las mujeres, al riesgo de promiscuidad y, en última instancia, a la incompatibilidad congénita e irremediable de lo femenino con la esfera pública. Es elocuente la ilustración maliciosamente titulada "II Rapporto" (Figura 2), que representa a una guardia cívica en pose de saludo militar a su superior, la cual yace en un diván con mirada lánguida, el pecho entreabierto y un ramo de flores en la mano; un sombrero masculino sobre el lecho revela la presencia de un hombre apenas oculto. El diálogo inserto al pie como subtítulo completa la poco velada alusión:

Cittadina generale, hanno deciso per l'unione immediata!.. Vi era già predisposta... 


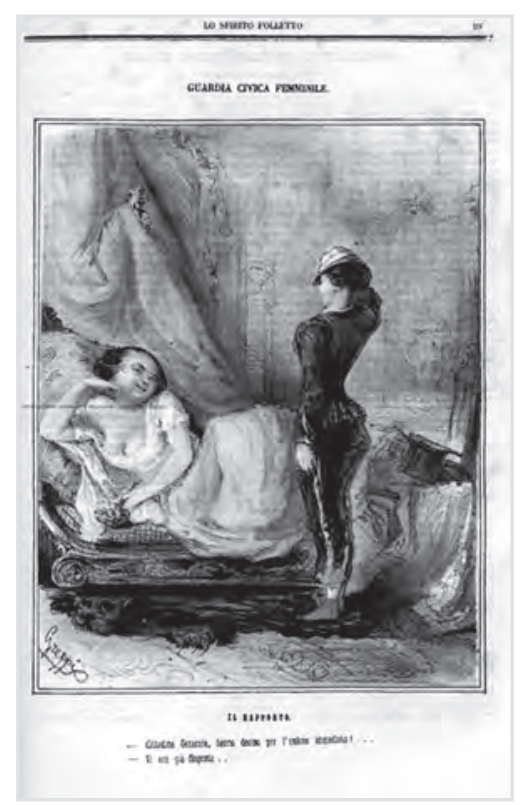

Fig. 2.

La ironía misógina de la ilustración resulta aún más estridente si se considera la situación política del Milán de aquel tiempo, ferozmente dividido por la elección entre la unión inmediata al Piamonte o el aplazamiento de la decisión hasta después de la guerra (por cierto, la posición que sostuvo ese periódico), así como la brecha entre el Gobierno provisional y una gran parte de la opinión pública de la ciudad. ${ }^{30}$ Para confirmar el tono misógino y segregacionista de los dibujos del periódico milanés, unos días antes se había publicado otra ilustración (Figura 3) -de las cinco en total que componen la serie sobre la Guardia Civica Femminile- que representa a las cívicas enfundadas en uniformes especialmente estrechos -para subrayar deliberadamente las formas femeninas-e intentando seguir las órdenes de una superior, seguramente en el contexto de un desfile o una parada.

30 CATTANEO, Carlo (1849), Dell'insurrezione di Milano e della successiva guerra, Tipografia della Svizzera Italiana, Lugano, pp. 107 y ss. 


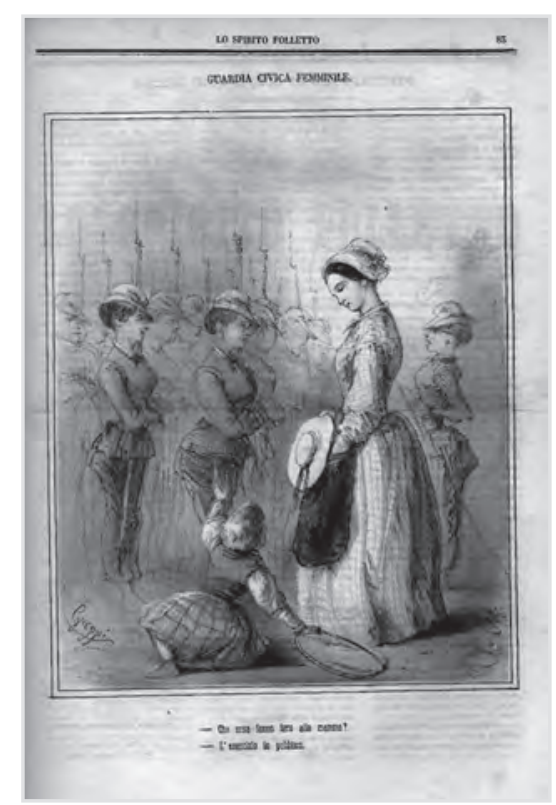

Fig. 3.

Una niña le pregunta a su nodriza, esta sí, vestida casta y correctamente, "che cosa fanno fare alla mamma?". La respuesta, que redondea el significado del grabado, contiene y al mismo tiempo muestra la peligrosidad del momento: "L'esercizio in pubblico", responde plácidamente la mujer. Como en "Il Rapporto", se subraya la dimensión antisocial de la presencia pública visible de las mujeres, pero en este caso no se invoca el amor erótico -aun así, presente en el resaltado de la sinuosidad de los cuerpos-, sino los aspectos familiares, resaltando los riesgos de la promiscuidad y del protagonismo femenino en el ámbito público y, como sucede aquí, en el privado. Como explicaré más adelante, este énfasis es sustancial.

De todos modos, la mujer, entendida como asunto o tema ilustrativo, no se limita a esta finalidad. Más bien, y como exponente de las características de los diversos aspectos de lo femenino (debilidad, vanidad, falta de autocontrol, ausencia de autonomía), las mujeres se convierten en actrices que se mueven en una escenografía enmarcada en el canon nacional-patriótico y que tiene el cometido de impulsar y conservar el honor de Italia. Por ejemplo, en "Oltraggio e punizzione" (Figura 4), de Massutti, aparecida en Don Pirlone a Roma, la presencia de una mujer, indefensa y molesta ante la imagen salvaje de un invasor con aspecto diabólico, ofrece una oportunidad para el rescate del honor privado y del nacional. El grabado se libera 
esta vez del componente alegórico, residual, en beneficio de un discurso descriptivo que obtiene su fuerza del sistema narrativo de la referencia, de la alusión evidente a la tradición de las Vísperas Sicilianas. ${ }^{31}$ Aparece así en escena la masa popular, como héroe impostado. Ante la insoportable visión de las

vittime quotidiane [inmoladas] alla vendetta dei barbari, e la libidine soldatesca invidiava ai cittadini più che la vita, attentando all'onor delle donne con inaudita violenza. Ma il braccio del popolano fece più d'una volta giustizia della insana licenza, e nel sangue dell'osceno croato lavò sovente l'oltraggio. ${ }^{32}$

El valore italiano, como lo llama el tándem en el grabado ilustrativo, surge aquí en defensa del honor, tanto de las mujeres como, en respuesta explícita a la acusación de afeminamiento, de los hombres en el campo de batalla.

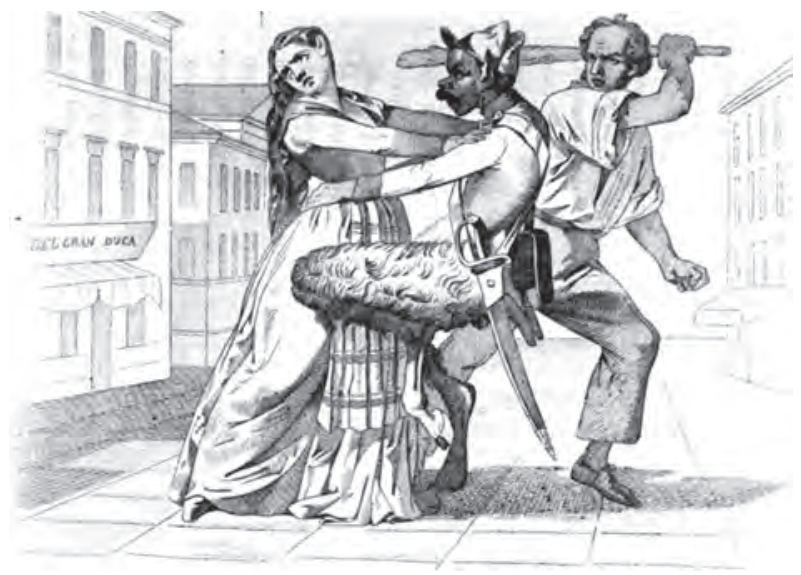

Fig. 4.

Al pasar de la caricatura al ámbito pictórico, el papel que representa el tema femenino en el esquema figurativo de las propuestas artísticas de los pintores-soldados se sitúa en línea de continuidad de ideas con lo que se ha visto en la ilustración satírica. Bastará observar la Trasteverina colpita da una bomba, de Gerolamo Induno (Figura 5) y el famoso cuadro de Odoardo Borrani Le Cucitrici (Figura 6).

31 MAZZOCCA, Fernando (1982), Invito a Francesco Hayez, Rusconi, Milán.

32 PINTO, Don Pirlone a Roma, vol. III, p. 109. 
Se trata de representaciones fuertemente imbuidas de sentido patriótico, donde el sujeto retratado es, justamente, femenino, y en las que el papel discursivo en/de la femineidad surge con total claridad. En el primer caso, la sorpresa y el horror desatados por la crudeza del cuadro residen tanto en el registro realista de Induno como, sobre todo, en la identidad de género de la víctima. Estamos, en suma, ante la representación del cuerpo sin vida de una joven mujer romana víctima de una bomba francesa, a pesar de que se mantuviera a cobijo, en la cocina de su propia casa. ${ }^{33}$ La efímera experiencia republicana había tenido lugar hacía poco, así que la presentación del cuadro en Brera logró un gran efecto, que impactó en la crítica y obtuvo -aspecto éste del todo relevante- un gran éxito de público. ${ }^{34}$

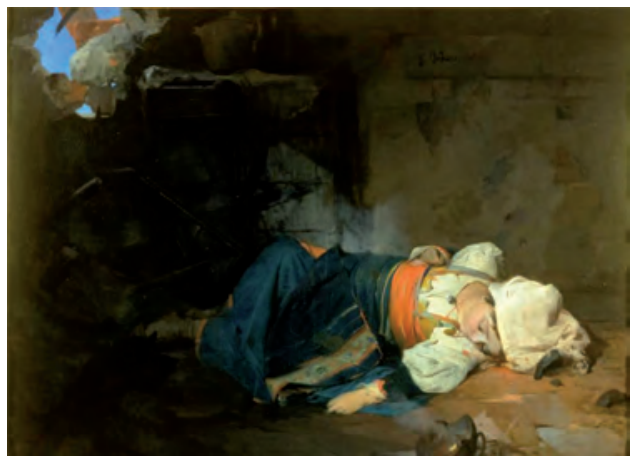

Fig. 5.

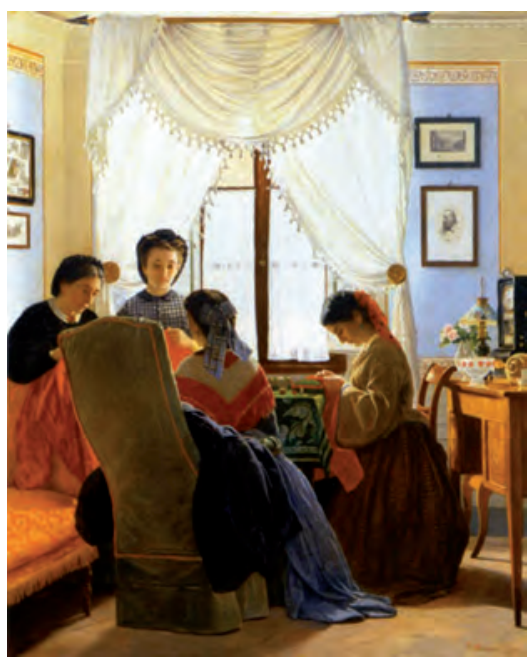

Fig. 6.

33 En palabras de Giuseppe Rovani, "Nella sua semplicità [la pintura] rappresenta un grande momento della vita contemporanea e l'immaginazione, per quell'unica figura, si vede innanzi la vasta scena delle solenni sventure dell'eterna città assediata" (ROVANI, Giuseppe (1860), "Esposizione di Belle Arti nel palazzo nazionale di Brera", Gazzetta di Milano, 259, 18 de septiembre de 1860. Es del mismo parecer la citada reseña publicada en La Società, que describe la imagen como un "episodio del glorioso assedio fatto dalle armi francesi a Roma [...] una bomba penetra nella stanza di una povera fanciulla e questa sta rovesciata in sul terreno immersa nel proprio sangue. II soggetto benissimo eseguito fa raccapricciare l'osservatore e deplorare le umane miserie" ("L'esposizione di Belle Arti", La Società, p. 53). Véase también la crítica del académico Antonio Zoncada, que volvió sobre el tema-la muchacha-, por bien 
Como escribió el crítico de arte Rovani, el de Induno era "un quadro che ti si imprime nella memoria e ti comanda la meditazione intorno ai fatti più tremendi della vita pubblica" 35 y que quedaba grabado tanto por su fuerza expresiva, su brutalidad y su "raccapriccio" (horror), , 36 como por el franco reconocimiento artístico de la contribución de todo el pueblo, mujeres incluidas, en la defensa de la Ciudad Eterna; de la puesta en escena, en fin, de los postergados y los olvidados. El éxito de público y el gran eco de la Trasteverina fue refrendado por la crítica oficial que publicó el periódico gubernamental Gazzetta Ufficiale di Milano y por los dictámenes de los expertos del ramo, ${ }^{37}$ como Carlo Tenca en las páginas de Crepuscolo. ${ }^{38}$ La eficacia del mensaje político -la brutalidad de los sitiadores y la justicia de la causa republicana y nacional- se aseguró mediante el recurso a la congénita debilidad femenina, a la mujer como depositaria del honor y garante de la descendencia patria; por lo demás, la juventud y la apelación a la tradición étnica romana incrementaban más si cabe la carga evocadora y emocional de la imagen. La de Induno es, en esencia, una construcción comunicativa que se mueve entre el plano racional -estilístico, técnico, temático, político...- y otro semiconsciente y atávico -lo que Ginsborg y Banti llaman el "spazio delle figure profonde" $-{ }^{39}$ de forma que se establece un vínculo entre la elección estilística y la temático-emotiva que garantiza la atención y el éxito del cuadro.

ejecutado, armónico y expresivo (ZONCADA, Antonio (1850), "Appendice. Esposizione di Belle Arti nel palazzo di Brera IV", Gazzetta Ufficiale di Milano, vol. 264, 21 de septiembre de 1850, p. 1.231). Cf. REGONELLI, Silvia (2006), "Risorgimento intimo. La trasteverina uccisa da una bomba di Gerolamo Induno", L'uomo nero. Materiali per una storia delle arti della modernità, III, vol. 4-5, pp. 357-373.

34 MAZZOCCA, 1861. I pittori del Risorgimento, p. 114.

35 ROVANI, Giuseppe (1850), Una parola sulla pubblica esposizione di Belle Arti, 1850, p. 293.

36 "L'Esposizione di Belle Arti del 1850", en La Società. Giornale di Letteratura, Arte, e Scienze Sociali, I, vol. 12, 8 de septiembre de 1850, p. 53.

37 Citado en MAZZOCCA, 1861. I pittori del Risorgimento, p. 114.

38 TENCA, Carlo (1850), "Esposizione di Belle Arti nel Palazzo di Brera. III", II Crepuscolo. Rivista Settimanale di Scienze, Lettere, Arti, Industria e Commercio, I, vol. 33, 22 de septiembre de 1850; citado en MAZZOCCA, 1861. I pittori del Risorgimento, p. 114.

39 GINSBORG, Paul y BANTI, Alberto Maria (2007), "Per una nuova storia del Risorgimento", en BANTI y GINSBORG (eds.), Storia d'Italia. Annali 22, pp. XXIII-XLI. 
Si en la Trasteverina el discurso sobre la femineidad se contrapone a un segundo nivel de lectura, más denso y de apreciación menos inmediata, se vuelve más didáctico en la pintura de Borrani: aquí, los sujetos femeninos se ven limitados a colaborar con la causa patriótica cosiendo banderas o camisas rojas en el seno de la plácida y segura calma doméstica, mientras a su alrededor otros elementos del mobiliario -la estampa de Garibaldi en la pared o la enseña tricolor- proporcionan indicaciones precisas para la interpretación. Es, en suma, el reconocimiento del papel femenino en las batallas, o quizá sería mejor decir para las batallas, del Risorgimento. Los hechos de armas y el protagonismo de Cristina Belgioioso y sus compañeras -aceptadas, aunque sea a disgusto y tan solo como excepcionesestán, en realidad, a años luz de distancia, y se permite la participación del universo femenino en el gran drama nacional solo a través de tareas honorables que se lleven a cabo en la penumbra del hogar. Aunque el panorama aparezca muy fragmentado y haya que rehuir cualquier generalización forzada, la donna nuova invocada, esperada (más probablemente, temida) que se plasma sobre el ideal de la virilidad masculina y difunden algunos periódicos patrióticos, parece más una abstracción literaria que el registro de una realidad efectiva, de forma que el protagonismo femenino adquiere un carácter de excepción.

\section{LA LITERATURA DE FICCIÓN}

En paralelo al resurgimiento del interés por la historia del Risorgimento, en los últimos veinte años, la novela histórica también ha entrado en el debate historiográfico, por un lado suscitando encendidas disputas metodológicas y por el otro alcanzando por diversas razones la categoría de fuente histórica creíble. ${ }^{40}$ De forma análoga a lo que se ha visto en la ilustración, también la producción literaria contribuyó de manera significativa a la lucha ideológica que se libraba aquellos años y estableció una asonancia

40 Se trata de un asunto complejo y muy debatido. Aquí me limito a señalar a GAY, Peter (2004), Nello specchio del romanzo. Dickens, Flaubert, Thomas Mann, Carocci, Roma; GAY, Peter (2002), Schnitzler's Century: the making of middle-class culture, Norton \& Co, Nueva York; HARLAN, David (ed.) (2005), Rethinking History, vol. 2-3 (2005), con textos de diversos autores; FOUCAULT, Michel (1996), "Che cos'è un autore?", en Scritti letterari, Feltrinelli, Milán; AUERBACH, Erich (1968), Mimesis: la représentation de la réalité dans la littérature occidentale, Gallimard, París; WATT, lan (2017), Le origini del romanzo borghese: studi su Defoe, Richardson e Fielding, Bompiani, Milán; y CAGLIOTTI, Daniela Luigia (2005), "In evidenza. Introduzione. Romanzo e storia", Contemporanea, vol.VIII:4. 
sintomática entre las consignas y las estrategias comunicativas en juego, lo que restituyó una cierta homogeneidad al discurso. Inmediatamente después del fracaso revolucionario, tanto los individuos más prominentes del nacionalismo moderado y democrático (Garibaldi, Sebregondi, Capranica, etc.) como el nuevo periódico La Civiltà Cattolica se consagraron a la producción del género literario más de moda, la novela histórica, un producto muy solicitado por un público -burgués- voraz y en expansión. En este contexto, la Curia romana comprendió perfectamente la importancia estratégica de este nuevo medio, y lo empleó para transferir contenidos políticos y morales entre líneas, casi al descuido, entreteniendo y dejando que los objetivos ideológicos se deslizaran por canales más ligeros, menos polvorientos y exigentes que las disquisiciones teológicas, y en consecuencia más eficaces y exitosos para la difusión pública. En este terreno, las dos plumas más célebres del periódico jesuítico fueron las de Antonio Bresciani y Giuseppe Franco, incansables soldados de Pío IX en la guerra sin cuartel contra la modernidad. Una gran parte de los temas que se han analizado en los apartados anteriores se hallan también en las páginas y las frecuentes conexiones intertextuales que estructuraron los textos reaccionarios y del Risorgimento.

George Mosse ha rastreado en el período napoleónico y revolucionario el surgimiento de un nuevo ideal europeo de virilidad heroica, cristalizado en las características masculinas del valor, la intrepidez y el autocontrol. Estos se consolidarían como elementos definitorios a lo largo del siglo XIX, en estrecha relación con la formación de los estados nacionales de base étnica, los cuales estaban intrínseca y necesariamente volcados en la búsqueda de las señas de identidad que caracterizasen la definición del relato, decisivo en el discurso nacionalista, de exclusión/inclusión. ${ }^{41}$ Por otra parte, Lucy Riall sostiene que a través de la acción bélica -sea en las filas del ejército regular o de las unidades de voluntarios- el sistema de valores viriles se define en términos físico-corporales, ya que "il guerriero moderno si pone al fianco del giovane greco", aunque se enriquece con narraciones artísticas y funcionales que definen un "mito dell'esperienza della guerra"

41 MOSSE, George (1997), L'immagine dell'vomo. Lo stereotipo maschile nell'epoca moderna, Einaudi, Turín, pp. 66 y ss. Véase también RIZZO, Domenico (2003), "Mariti e mogli adultere in età liberale", Genesis, vol. II, pp. 15-32; LANZINGHER, Margaret y RIZZO, Domenico (eds.) (2014), Il corpo della famiglia, II Mulino, Bolonia; BENADUSI, Lorenzo y CARAVALE, Giorgio (eds.) (2012), Sulle orme di George L. Mosse: interpretazioni e fortuna dell'opera di un grande storico, Carocci, Roma; y BENADUSI, Lorenzo (2015), Ufficiale e gentiluomo: virtù civili e valori militari in Italia (1896-1918), Feltrinelli, Milán. 
que "guarda al conflitto come a un evento carico di senso, positivo e anzi sacro". ${ }^{42}$ Sostiene Mosse que el estereotipo -producto de la hegemonía masculina-43 mantuvo su continuidad "dalla Francia rivoluzionaria fino alla seconda guerra mondiale". ${ }^{44}$ Por lo tanto, y en paralelo, como ha hecho notar Roberto Bizzocchi, ${ }^{45}$ durante el Risorgimento se asiste a una normalización de los equilibrios familiares y de la moral sexual y de género (fidelidad, independencia, roles, exposición pública), que se caracteriza por una progresiva erosión de la autonomía femenina y una rígida definición de roles, en el contexto más amplio de la afirmación de la sociedad burguesa: "polemica contro i valori cetuali di antico regime, adesione in chiave liberale e progressista al Romanticismo, importanza cruciale della maternità, serietà sentimentale e impegno di fedeltà fra coniugi con il rifiuto del cicisbeismo, severità dei costumi" ${ }^{46}$

Entrando ya en materia, lo que sorprende a un lector de hoy en el análisis de las novelas populares de fondo histórico o ideológico es la omnipresencia de la sexualidad, el recurso constante a las alusiones sexuales y la insistencia sobre la dimensión corporal de los personajes. En este aspecto no hay diferencias entre los textos reaccionarios y las obras patrióticas. En el universo del discurso de las novelas analizadas, lo físico-corporal es más que una figura retórica-una metonimia-: es una descripción o alusión que está ahí para otra cosa. En general, la belleza expresada literariamente es la medida de la catadura moral del personaje y, en consecuencia, el primer dispositivo de separación entre nosotros y los otros, entre personajes positivos y figuras antagonistas, lo que lo convierte en un instrumento, tan banal como eficaz, de búsqueda de empatía con el lector (y, claro, de persuasión ideológica). Sin embargo, la apelación a la belleza como termómetro ético y garantía de probidad -así como de afinidad ideológica- no debe entenderse en términos exageradamente esquemáticos, muy al contrario.

Un exponente revelador a este respecto son las descripciones de la femineidad, donde a menudo el énfasis en la belleza del personaje incorpora

42 RIALL, Lucy (2007), "Eroi maschili, virilità e forme della guerra", en BANTI y GINSBORG (eds.), Storia d'Italia. Annali 22, p. 257.

43 CONNELL, Raewyn W. (1996), Masculinities, Polity Press, Cambridge. Plantea un análisis cultural de la masculinidad nacionalista realizado a partir del modelo analítico gramsciano y de la noción de hegemonía.

44 MOSSE, George (1990), Le guerre mondiali. Dalla tragedia al mito dei caduti, Laterza, Roma-Bari, p. 7.

$45 \mathrm{BIZZOCCHI,} \mathrm{"Una} \mathrm{nuova} \mathrm{morale} \mathrm{per} \mathrm{la} \mathrm{donna} \mathrm{e} \mathrm{la} \mathrm{famiglia",} \mathrm{pp.} \mathrm{69-96.}$

46 BIZZOCCHI, "Una nuova morale per la donna e la famiglia", p. 90. 
un juicio de signo negativo, que se vuelve legible a través de un repertorio específico de señales, referidas de diversos modos a la sensualidad. Así, la belleza ya no es una metonimia, sino que se limita a ser una propiedad de lo femenino, y las señales interpretativas -la sensualidad insinuantedesempeñan una función de indicadores de moralidad. En este sentido, la ausencia o presencia de connotaciones explícitamente sexuales insertas en la descripción indican la posición que ocupa el personaje femenino en la estructura narrativa y en el sistema de valores de la novela. En el Prode di Roma de Francesco Sebregondi, la duquesa, figura negativa y tentadora, se distingue por su belleza femenina y por su-asimismo femenina- peligrosa e impía frivolidad:

Alta della persona, il moto del suo passo avea qualche cosa del maestoso, che nulla toglieva alle grazie irrequiete di due anche da statua greca, [...] la vedemmo appoggiata all'angolo di quel camino, con uno sguardo forse troppo curioso, indovinammo a bella prima che, nelle sue pose, la nobil donna sapea accoppiare la severità del sussiego all'enigmatico vezzo di una plastica piaggeria. [...] Ella rivolse a Ugo tale uno sguardo pieno di fascino e di passione, che parea volesse tradurre l'atto d'amnistia in un abbandono di tenerezza. Le sue labbra si apersero ad un sorriso di voluttà indescrivibile; il bulbo di quegli occhi divini nuotava nel glutine azzurro della donna che si oblia [...] appoggiando lievemente la sua bella testa sul dossiere del divano, parea dicesse: la schiava perdona al suo dominatore. ${ }^{47}$

El fragmento citado es emblemático porque condensa el arsenal narrativo y estratégico que se reserva a lo femenino en la novela histórica de actualidad, una panoplia discursiva que, vista la omnipresencia explícita o latente de la sexualidad y la centralidad de la mujer, configura esta tipología textual como un decálogo de deberes y prohibiciones de género.

Es asimismo representativo de la función novelesca de la feminidad el capítulo "Le due cognate", que Bresciani incluyó en su best seller para proporcionar, desde la óptica de la mujer, una lectura política autoevidente, que se logra gracias a la yuxtaposición de dos modelos femeninos antitéticos. Como ha señalado Paolo Orvieto, las dos cuñadas romanas Laura y Metilde, "una tutta bianca e una tutta nera", brindan el "pretesto per una

47 SEBREGONDI, Francesco (1864), Un prode di Roma (1849-1862), G, Brigola, Milán, pp. 214 y 247. 
infervorata discussione" política y antifeminista: en las mujeres, sostiene el jesuita, "le idee sbagliate si radicano più facilmente e sono più difficilmente estirpabili, perché le donne, meno intelligenti, meno razionali e assai più cocciute dell'vomo, sono più facili da convincere e più difficili a ravveder-

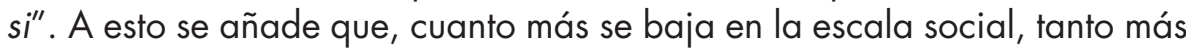
las mujeres son de "corti intelletti", por ello de más fácil conversión a las ideas liberales $y$, en fin, argumenta Bresciani con una vena misógina nunca desmentida, equiparables a "galline che covano vova di serpenti". ${ }^{48}$

Los personajes femeninos brindan, por tanto, la oportunidad de una definición del campo de supremacía política y las connotaciones de moralidad de una opción ideológica respecto a la otra: una moralidad reafirmada por la señalización de tipo sexual. Así, la mujer maléfica -sea la reaccionaria duquesa del Prode di Roma o la infernal mazziniana Babette- se vincula necesariamente a actitudes sensuales y a prácticas impropias -como la lectura de obras prohibidas: "ciò che per Eva fu il pomo vietato, per Eleonora è stata invece la cronaca dell'OEil de boeuf" $-{ }^{49}$ o la exposición pública del propio cuerpo en el caso de la bailarina Polissena. Como contraste, en los textos jesuíticos las figuras femeninas positivas son la base para la recomposición del equilibrio novelesco, que se consigue con el arrepentimiento, y la consiguiente confesión y/o conversión. Por otro lado, el análisis intratextual de las novelas históricas revela una meticulosa enumeración de los elementos de la conducta femenina aceptable. Las lecturas francesas son catalogadas como "pessimi libri", 50 porque representan para las muje-

48 ORVIETO, Paolo (201 1), Buoni e cattivi del Risorgimento: i romanzi di Garibaldi e Bresciani a confronto, Salerno Editrice, Roma, p. 121.

49 SEBREGONDI, Un prode di Roma, p. 217. Otro pasaje del texto confirma la insistencia en la dimensión sexual de la mujer y el peligro de su lascivia apasionada. El uso de un registro hiperbólico y alusivo transforma un pensamiento romántico en la transposición literaria del orgasmo: "L'Olimpo schiude le porte; Ebe versa nelle coppe dei nimbiferi immortali il nettare celeste; ai concenti della lira d'Orfeo risponde dal bosco il verso fescennino sacro al figlio di Urano e di Vesta. Le orgiasti sacerdotesse scuotono il tirso a iniziano il mistero di Bacco; la bianca Giunone scioglie la chioma profumata; Minerva lascia cadere sul pavimento dell'egiaco padre il rabescato peplo; gli dei tripudiano, e il bellissimo torso dell'Apollo di Belvedere stupendamente inciso da bulino maestro, e su cui la stanca sognatrice lasciò cadere la vellutata carta velina, a poco a poco scompare dietro una nebbia biancastra.... si sfuma... l'apoteosi della materia si compie sotto le volte dell'empireo pagano. I contorni dell'antica scollatura ammaliarono l'incauta: la materia soffoca, si contorce, divampa; il pensiero crea, soffre e si corrompe" (p. 218).

50 PICCHIORRI, Emiliano (2008), La lingua dei romanzi di Antonio Bresciani, Aracne, Roma, p. 25. 
res lo que "fu per Eva il pomo vietato" e inducen a las lectoras inexpertas, "siccome è uso al gentil sesso", 51 a la ligereza frívola, en tanto que el teatro, la música y sobre todo el baile son nada menos que lo propio de una "diavolessa" o una "baccante". ${ }^{52}$ La exclusión del elemento femenino de la vida social activa, prerrogativa masculina, queda plenamente de manifiesto en un fragmento del Prode di Roma. Aquí la duquesa, acostumbrada a las lascivias de las lecturas frívolas, mancilla doblemente el sagrado pacto matrimonial: no solo trastoca la natural subordinación respecto al marido, sino que llega a atentar contra su honor al ofrecerse carnalmente al revolucionario Ugo:

La duchessina [...] si scioglieva le ordelline dell'angusto corsetto per svestirsi [...]. Era elaterio dell'animo, era fuoco delle vene quello che placava la dea magnanima? Lo sapremo: il fatto sta che si diede ad ondeggiar tra il bene e il male, come una nuova Eva pronta ad ascoltare per una seconda volta il serpente; e ad ogni gonna che leggiadramente le cadea giù dalle duttili anche per aggrovigliarsi attorno ai piedi d'avorio, dessa diveniva sempre più mite e men fiera. Quando sentì il diffuso volume delle sue chiome sciogliersi sulle spalle nevose, provò un brivido per tutte le ossa, mandò un sospiro e strinse finissime le labbra. ${ }^{53}$

El protagonista Ugo, no hará falta decir que dotado de la contención viril que caracteriza a los personajes positivos de la literatura de consumo, resiste a la tentación, "perdonandola" ${ }^{54}$ La convicción de lo peligroso de la libertad extradoméstica femenina presupone la de su minoría de edad intrínseca y confirma el riesgo que representa la subversión de los roles. Los modelos positivos que se proponen son, en realidad, argumentos para propugnar y estimular el "pudore di donna", ${ }^{55}$ la morigeración,, la hu-

51 GARIBALDI, Giuseppe (1870), Clelia, ovvero il governo del monaco (Roma nel XIX secolo), Fratelli Rechiedei, Milán, p. 169.

52 SEBREGONDI, Un prode di Roma, p. 65.

53 SEBREGONDI, Un prode di Roma, p. 113.

54 SEBREGONDI, Un prode di Roma, p. 114.

55 GARIBALDI, Clelia, p. 176.

56 PICCHIORRI, La lingua dei romanzi di Antonio Bresciani, p. 388. 
mildad como esencia de la femineidad y, por ende, la sumisión esencial al marido. Todo ello queda modélicamente sintetizado en la figura de la púdica Irene de Clelia -una novela escrita nada menos que por Giuseppe Garibaldi-, cuando al hablar de su consorte asegura "sentivo di esser sua, ed egli avrebbe potuto disporre di me come d'una schiava" ${ }^{57}$ En lo que a la condición femenina respecta, los textos aquí considerados consiguen un efecto paradójico: a la centralidad (aunque casi nunca protagonismo) de las mujeres, siempre muy clara en la arquitectura novelesca, le corresponde sin embargo su marginación social y de género.

Hay que hacer también una breve mención al honor y a la pureza de sangre cuando se trata del papel de las mujeres en la trama romántica. Como ha subrayado Banti, que en esto se alinea con George Mosse, la femineidad representa la estratagema para trazar rígidas líneas de división y selección étnicas, la contraposición biológica y sexual entre nosotros y los otros, con una función nacional y xenófoba (el croata, los franceses de las Vísperas Sicilianas, etc.) o, en los casos aquí examinados, con finalidades políticas (demostrar la abyección del jesuita o la inmoralidad del sectario). La violación o el intento de violación, contempladas como prácticas asiduas, se reservan para la demonización del adversario ideológico, con su representación caricaturesca e inhumana: baste pensar en el mazziniano Lionello, que comete infanticidio tras un rechazo carnal. ${ }^{58}$ Se hallará la misma respuesta en las páginas de Clelia donde, además de delinearse los rasgos satánicos y amorales del violador adversario, se toma del canon el imperativo categórico de la pureza, hasta llegar al suicidio por deshonor:

Invano egli la supplicò, adoperando tutte le lusinghe di cui era capace - sempre più fieramente le rispondeva la nostra eroina - laonde - furioso il prete che vedeva scorrere il tempo senza approdare a nulla [...]. Clelia trasse risolutamente il pugnaletto - e mentre furibonda e con voce commossa esclamava: "Piuttosto m'immergerò questo ferro nel cuore. ${ }^{59}$

57 GARIBALDI, Clelia, p. 177.

58 Por otra parte, Lionello o delle società segrete ha sido interpretado como una respuesta a la Vita di Garibaldi de Giovanni Battista Cuneo. PICCHIORRI, La lingua dei romanzi di Antonio Bresciani, p. 47.

59 GARIBALDI, Clelia, cit. p. 91. 
Como han sostenido Banti y Bizzochi, durante el siglo XIX se establece una nueva moral familiar, que se contrapone a las licenciosas costumbres aristocráticas del Ancien Régime, bien documentadas en los estudios de Michel Vovelle o Robert Darnton. ${ }^{60}$ La nueva perspectiva de lo doméstico responde a la necesidad de dar a los hijos una educación hecha de cuidados amorosos y no de liviandades, que sea capaz de forjar -no necesariamente solo en un sentido nacional- una nueva generación de hombres ( $y$, funcionalmente, de mujeres). No se hacen concesiones a los placeres carnales extraconyugales, a los que se considera una práctica antisocial: así, la mujer tiene que ser "pudica", ${ }^{61}$ "umile", 62 "pura", "casta, ideale", tiene que rechazar la lascivia, la indolencia y la frivolidad que en principio le son congénitas, ${ }^{64}$ para consagrarse a su mayor deber. Es de lo más explícito este fragmento de la obra de Sebregondi, que combina lo naïf con el orgullo patriarcal:

Povera creatura che è la donna! Ella non vede che famiglia e pace, non riposa il suo pensiero che negli affetti materni, e noi se l'incontriamo in un ballo non le parliamo altro che della sua eleganza e delle sue grazie, e non mai de' suoi figli; e sì che in essi sta tutta la sua esistenza! 65

La moralización de la sociedad se liga doblemente al discurso nacional, que tiene su más firme puntal en la regeneración biológica de la especie y en la figura normalizada de la mujer-madre; el atentado contra la sexualidad femenina representa una amenaza para toda la comunidad de

60 DARNTON, Robert (1997), Libri proibiti: pornografia, satira e utopia all'origine della rivoluzione francese, Mondadori, Milán; VOVELLE, Michel (1989), "La "coda" di Danton o massacro e sessualità: violenza e fantasmi erotici nelle letture della Rivoluzione francese", en Immagini e immaginario nella storia. Fantasmi e certezze nelle mentalità dal medioevo al Novecento, Editori Riuniti, Roma, pp. 239-247; y BANTI, Alberto Mario (2016), Eros e virtù. Aristocratiche e borghesi da Watteau a Manet, Laterza, Roma-Bari (edición digital), 2016.

61 GARIBALDI, Clelia, p. 176.

62 SEBREGONDI, Un prode di Roma, p. 56.

63 GARIBALDI, Giuseppe (1870), Cantoni il volontario. Romanzo storico, Kaos edizioni, Milán, (ed.2006), p. 240.

64 CAPRANICA, Luigi (1857), Giovanni delle bande nere, Dalla Tipografia del Commercio, Venecia, vol. II, p. 116.

65 SEBREGONDI, Un prode di Roma, pp. 396-397. 
sangre y se convierte en un motor retórico del nacionalismo y de toda su eficacia comunicativa. La dimensión familiar de la mujer se combina con la vocación y las necesidades de la nación, que recaen en la figura de la esposa y madre, de la que se espera, además de otros cometidos biológicos esenciales, que inculcará el amor a la patria. Así, "la creatura santa delle pareti domestiche" 60 que con "il primo bacio della madre incide sulla fronte dell'vomo l'onore", 67 es compelida a celebrar " $i$ valorosi, $i$ vincitori dell'oppressore" -"beateli!"-, ya que estas"[queridas mujeres] son degni di voi, del vostro sorriso, del vostro amplesso e dell'amor vostro! Essi sparsero il loro sangue, cimentarono la loro vita per non lasciarvi ludibrio a sgherri". ${ }^{68}$

Ilaria Porciani ha escrito que "un momento centrale -forse il più decisivo- per la costruzione della coppia famiglia-nazione è il 1848", ${ }^{69}$ no solo porque las mujeres estuvieron en las barricadas y tomaron parte en las grandes liturgias públicas, sino porque en esta divisoria histórica se consolidó y certificó una refundación de las costumbres, una redefinición de los roles acuñados sobre las virtudes privadas que, al hilo de las reflexiones de Rousseau y Montesquieu, pasaron a considerarse "una conquista indispensabile a restituire dignità e credibilità alla comunità di appartenenza" ${ }^{70}$

Bien mirado, el análisis intertextual de novelas ligeras con antecedentes históricos ofrece una definición rígida del papel de la mujer en una perspectiva social y étnico-nacional más amplia. Las figuras femeninas positivas se mueven en el escenario único de la intimidad familiar, a cubierto de "occhi indiscreti", ${ }^{71}$ se dedican a engendrar hijos, a educarlos y a confortar, en funciones estrictamente auxiliares, a maridos, padres y hermanos. Lo que más sorprende, sin embargo, es la casi total coincidencia a este respecto entre los registros utilizados en los textos reaccionarios y en los patrióticos. La mujer -un lexema que en las figuras positivas conoce una transfiguración sinonímica que lo transforma en madre- es el "cuore d'angiolo per le delizie della sua famiglia", ${ }^{72}$ vive su "apostolato di amore celestiale"

66 SEBREGONDI, Un prode di Roma, p. 488.

67 SEBREGONDI, Un prode di Roma, p. 464.

68 GARIBALDI, Cantoni, p. 213.

69 PORCIANI, "Disciplinamento nazionale e modelli domestici nel lungo Ottocento", p. 115.

70 SOLDANI, Simonetta (2007), "II Risorgimento delle donne", en BANTI y GINSBORG (eds.), Storia d'Italia. Annali 22, p. 185; y McCLINTOCK, Anne (1993), "Family feuds: gender, nationalism and the family", Feminist Review, vol. 44, pp. 61-103.

71 SEBREGONDI, Un prode di Roma, p. 83

72 GARIBALDI, Clelia, p. 7. 
como "pura consolatrice dell'vomo" y educadora en la "santa famiglia".$^{74}$ Para corroborar esa centralidad asignada a la dimensión doméstica valga el caso de Beniamina, de Giovanni Giuseppe Franco: aquí las peripecias, las vicisitudes y los sufrimientos que envuelven a la piadosa protagonista se imputan, no solo a la indudable seducción liberal, sino también y sobre todo a la labor educativa y de control que ha descuidado la madre de Luisella, la antiheroína. Por eso, en el epílogo pedagógico que sigue a la muerte, una vez convertida, de la antes sectaria Luisella, Franco hace pronunciar a don Catone unas palabras que suenan a la vez como una advertencia y como una conminación

Fatta celebrare per l'anima di lei una Messa di requiem, nella quale tutte e quattro si comunicarono, furono poscia in sagrestia per depositarvi le candele, che doveano ardere all'altare della Vergine. Fra Catone, che era venuto apposta per confortarle, ed avea offerto il Sacrifizio, cercava di loro suggerire alcune ragioni di rassegnazione: la Marianna gli rispose: - Padre, voi speravate che la Madonna avrebbe ricondotto quella poveretta pentita a suoi piedi. Ora, bontà di Dio, pentita e ravveduta è stata; ma á piedi della Madonna non potendo essa, ha desiderato prima di morire, che venissimo noi in sua vece; ed ecco che fare quel pellegrinaggio fallito allora...- Volea dire di più; ma fu interrotta da singhiozzi, ai quali si accoppiarono le lagrime ancora delle fanciulle. Il buon religioso si argomentò di racconsolarle del suo meglio; e fini col dire: - Basta! Se non ci fossero i grandi peccati, noi neppure conosceremmo le grandi misericordie; e ad ogni modo i traviamenti di quella poveretta potranno servire alla istruzione di molte madri. - La quale ultima parola fra Catone proferì con particolare espressione, affissando severamente la Marianna, certo per ammonirla, che delle colpe e delle sventure della figlivola una qualche ammenda restava a fare anche a lei. ${ }^{75}$

73 FRANCO, Giovanni Giuseppe (1863), Le cospiratrici, Immacolata Concezione, Módena, p. 170.

74 GARIBALDI, Clelia, p. 3.

75 FRANCO, Giovanni Giuseppe (1866), "Beniamina", en Sei racconti, Pietro di G. Marietti, Turín, (3a ed.), vol. I, p. 337. 


\section{CONCLUSIONes}

Las tipologías documentales analizadas devuelven el uso de lo femenino en la historia revolucionaria con una frecuencia casi obsesiva, una insistencia que se despliega en al menos tres niveles. Primero, el de los elementos estilísticos figurativos, que ven la patria representada alegóricamente en el cuerpo de una mujer con el pecho descubierto y la cruz en la mano (Figura 7), un emblema artístico del nacionalismo italiano del siglo XIX que se refiere a la función generadora y educativa de la patria. En segundo lugar, lo femenino se usa como una estratagema narrativa (vuélvase a los textos de Bresciani analizados en este ensayo) para definir la bondad o no de cada opción ideológica, enriqueciendo la moralidad con el elemento político a través del comportamiento, bueno o malo, de los protagonistas. Así, las lecturas peligrosas e indecorosas en francés sancionaron el engaño de Mazzini "della infernale Babette", mientras que el digno y modesto rechazo del adulterio de la Clelia garibaldina confiere virtud y honor, no solo al protagonista, sino también a la causa nacional.

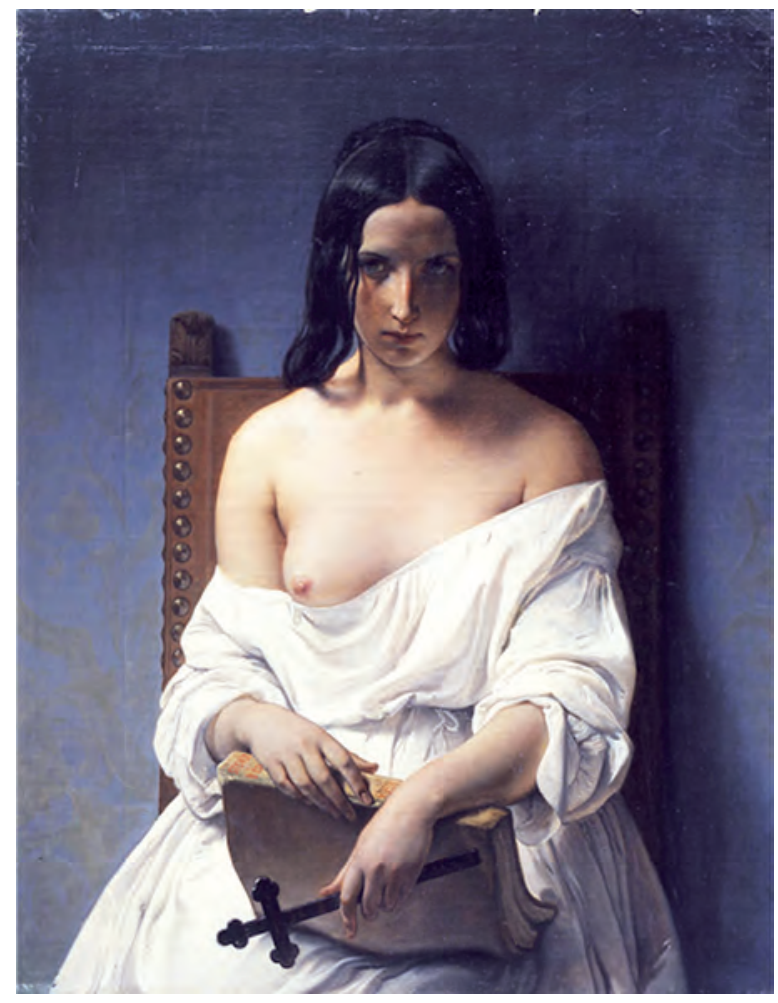

Fig. 7. 
La última consideración permite pasar al tercer y más importante punto de partida hermenéutico, que es la fisionomía social que estos medios parecen postular y/o proponer y en los cuales la mujer aparece como el eje indiscutible. La figura femenina queda encerrada, pues, en los muros domésticos, donde encuentra su lugar de elección y su realización, como generadora y educadora de los niños -"I'angello della famiglia" según Mazzini-, a los que la retórica nacionalista quiere saludables, fuertes y viriles, capaces de crear esa comunidad de armas requerida para construir y defender la patria. Esta, además, se configura como un territorio de hegemonía exclusivamente masculina. Salvo algunas excepciones esporádicas, la presencia de las mujeren en público y su participación activa en la vida política y social se consideraron inconvenientes, cuando no peligrosas y antisociales, tanto por la insuficiencia femenina congénita para administrar la res publica (Figura 2) como por el riesgo de presentarse ante la mirada del otro (Figura 3), arriesgándose a violar el vínculo sagrado del matrimonio, el fundamento de la familia nuclear burguesa y la comunidad de sangre invocada por el nacionalismo. Así adquieren significado las apelaciones obsesivas a la pureza de la sangre y la defensa del honor, tanto en la función xenófoba (Figura 4) como en lo tocante a la respetabilidad familiar. La cuidadosa atención y la convergencia que se registran en las diversas producciones y que atraviesan todos los medios aquí explorados certifican el papel central -aunque, por supuesto, en una función pasiva y subordinada- reconocido a las mujeres, comow ángeles guardianes del universo doméstico y familiar, que tanto el nacionalismo como el clericalismo valoraron como el cimiento de la nación y su reserva espiritual. 